\title{
DIAGNÓSTICO DA ARBORIZAÇÃO URBANA DA CIDADE DE CACOAL-RO
}

\author{
Juscidalva Rodrigues de Almeida1, Celso Gonçalves Barbosa ${ }^{2}$ \\ (recebido em 25.06.2009 e aceito para publicação em 23.03.2010)
}

\begin{abstract}
RESUMO
Os problemas com a falta de Planejamento da arborização urbana são evidentes nas cidades. Com o intuito de verificar a situação atual da arborização urbana no município de Cacoal, o presente trabalho teve como objetivo analisar e realizar o levantamento quantitativo das espécies existentes, as condições da arborização urbana em relação aos seguintes aspectos: disposição das árvores sob fios de energia elétrica, danos a calçadas e a distância das árvores quanto aos postes de iluminação, entrada de garagem e esquinas arborizadas. Teve como resultado 20 famílias botânicas e 45 espécies, sendo que dos 1479 indivíduos arbóreos levantados,1151 indivíduos encontram-se nas famílias Chrysobalanaceae (oiti), 386 e Moraceae (fícus), 765. Quanto à disposição das árvores sob a fiação elétrica 56,10\% tocavam a fiação pondo em risco a vida humana. Quanto aos danos causados a calçadas $60,79 \%$ das árvores avaliadas causaram algum tipo de dano. Foram encontradas 853 árvores plantadas irregularmente, 722 quando se toma como base à distância entre estas e as garagens residenciais e 131 árvores em relação à distância destas às esquinas. Perante os dados apresentados anteriormente a arborização não esta adequada, gerando prejuízos econômicos e colocando em risco a população.
\end{abstract}

Palavras-chave: Arborização, vegetação urbana, paisagismo.

1. Bióloga, Pós-graduada em Educação e Gestão Ambiental pela Faculdade de Ciências Biomédicas de Cacoal - FACIMED -RO, juscidalvarodrigues@yahoo.com.br ou bióloga.2008@hotmail.com 2.Orientador, Engenheiro Florestal, MSc - Docente da Faculdade de Ciências biomédicas de CacoalFACIMED - RO. 


\title{
URBAN AFFORESTATION DIAGNOSIS OF CACOAL CITY
}

\begin{abstract}
The problems with lack planning of urban afforestation are clear in the cities. In order to verify the current situation of urban afforestation in Cacoal City, the present study aimed to analyze and perform the quantitative survey of existing species and the conditions of urban afforestation related to the following aspects: Trees disposal under electric power lines, damage to the sidewalks and trees distance from the light poles, garages entrances and afforestated corners. Resulted in 20 botanical families and 45 species, knowing that 1479 of the individual trees researched, 1151 individuals are in the Chrysobalanaceae (Licania) 386 and Moraceae (fig tree), 765 families. About trees alocation under electric wires $56.10 \%$ touched the wires, endangering human lives. About the damage to sidewalks $60.79 \%$ evaluated trees, caused any kind of impairment. There were found 853 improperly planted trees, 722 based on its distance to the residential garages and 131 trees based on its distance to street corners. By the previous reported information the afforestation it's not appropriated, causing economic losses and endangering the population.
\end{abstract}

Keywords: afforestation, urban vegetation, landscaping.

\section{INTRODUÇÃO}

Com a necessidade de amenizar os grandes impactos ambientais nas cidades causados pelas edificações, o homem vem tentando criar ambientes que amenizem tais danos, entre eles a arborização das ruas, praças, parques, utilizando muitas vezes espécies exóticas e nativas.

As árvores e florestas apresentam função e capacidade de resfriar a terra, ou seja, o ambiente próximo e dentro das cidades gerando benefícios à população como proteção contra a ação dos ventos, diminuição da poluição sonora, absorção de parte dos raios solares, sombreamento, ambientação a permanências dos pássaros urbanos, diminuição da poluição atmosférica, neutralizando o excesso de dióxido de carbono, purificando o ar e melhorando a saúde física e mental da população, (PIVETTA e SILVA FILHO, 2002).

Segundo Bortoleto, Silva Filho e Lima (2006), muitas cidades brasileiras não possuem um planejamento adequado de arborização urbana, muitos projetos baseiam-se em métodos puramente empíricos, desprovidos de um conhecimento real do assunto. Como 
conseqüência dessa inadequação, a arborização empreendida mostra-se ineficaz, pois os benefícios que poderia, potencialmente, proporcionar à população não são observados.

Estudos realizados por Michi e Couto (1996), revelam que a população da cidade desconhece aspectos importantes quanto às árvores de ruas. Os moradores devem ser instruídos quanto às espécies mais indicadas e suas características, locais apropriados para adquirir as mudas, locais e forma de plantio, tutoramento, cuidados necessários e, principalmente, quanto à importância da arborização das cidades, da necessária formação de parcerias entre órgãos públicos e universidades de pesquisa, com o objetivo de melhorar as características da arborização urbana das cidades brasileiras.

Em função dessas necessidades faz-se necessário uma pesquisa sobre o modo como a arborização urbana é conduzida nas ruas e avenidas levando em consideração as espécies de árvores nativas existentes na área, o local onde as espécies são plantadas, as limitações locais, danos causados pela introdução das espécies que apresentam problemas (danos à rede elétrica ou telefônica e calçamento da cidade) (CEMIG/IEF, 2001). De forma que a arborização venha proporcionar a população uma cidade bonita, bem arborizada e não provocar danos à comunidade urbana.

A implantação de árvores nas áreas urbanas é de suma importância, mas é necessário tomar certos cuidados ao fazer o plantio dessas árvores. A falta de planejamento da arborização urbana tem provocado alguns danos à população, tais como interferências no sistema de distribuição de energia elétrica, risco à vida humana no momento da poda, danos no calçamento das ruas e avenidas entre outros.

Em razão destes problemas é necessário que haja projetos de como arborizar a área urbana de forma correta, reduzindo os gastos exagerados com podas e prejuízos causados nas redes de energia elétrica, proporcionando a população ambiente agradáveis dentro da sua cidade.

O objetivo deste trabalho foi fazer um levantamento e análise da arborização de Cacoal, partindo da necessidade atual de informações que permitam o planejamento de uma arborização que se ajuste às condições climáticas e ao espaço físico, mostrando a importância de um plano de arborização que valorize o aspecto paisagístico ecológico com a utilização de espécies nativas e exóticas de formas adequadas e compatíveis com as características físicas da cidade.

Perante a importância da arborização para o bem estar da população, a carência de literatura especializada e os danos causados pela arborização urbana mal conduzida, este trabalho vem levantar as condições atuais da arborização urbana de Cacoal de forma a gerar informações que possibilitem um planejamento de forma mais eficiente. 


\section{MATERIAIS E MÉTODOS}

\section{1 - Caracterização da área de estudo}

A área de estudo consiste nos Bairros residenciais, Novo Cacoal, Novo Horizonte, Jardim Clodoaldo, Princesa Izabel, e um bairro comercial o centro da cidade com o total de 14 ruas e 12 avenidas, sendo a rua e avenida definida através de sorteio, situada no município de Cacoal. "Este por sua vez, está localizado a uma latitude 1126'19” sul e a uma longitude 6126'50" oeste, estando a uma altitude de 200 metros, representando $1,6 \%$ do Estado, distante a $470 \mathrm{~km}$ da capital, Porto Velho. Limita-se ao norte com: Mato Grosso, ao sul: Rolim de Moura e Pimenta Bueno, ao leste: Espigão D' Oeste, ao oeste: ministro Andreazza, Presidente Médici e Castanheiras. (KEMPER, 2002).
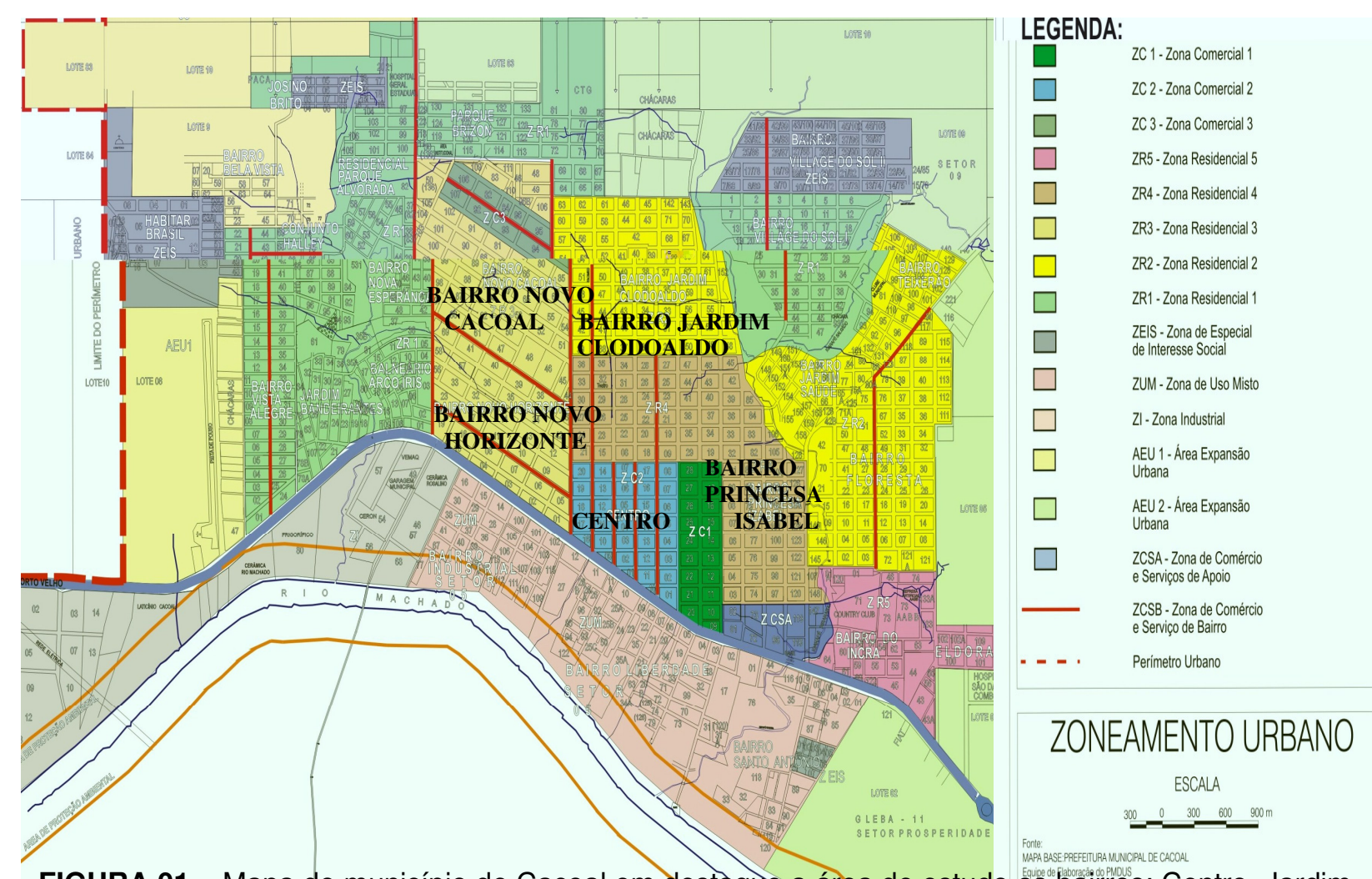

FIGURA 01 - Mapa do município de Cacoal em destaque a área de estudo os bairros; Centro, Jardim Clodoaldo, Princeza Izabel, Novo Cacoal, Novo horizonte.

Fonte: Prefeitura Municipal de Cacoal, 2009.

Kemper, 2002, afirma que o município de Cacoal possui uma área geográfica de 3, $805,5 \mathrm{Km}^{2}$. O clima predominante na região é tropical, quente e úmido, com duas estações: verão chuvoso e inverno seco. A temperatura é de 25으 $\mathrm{C}$, a vegetação predominante é floresta densa, tipo amazônico, o principal rio é o machado que é formado pela junção das águas do rio Barão de Melgaço e Pimenta Bueno, Fazem parte também da hidrografia deste município pequenos rios(corgos) como: Tamarupá e Pírarara. 
De acordo com o censo do IBGE (2008), a população de Cacoal é de 78.263 habitantes ${ }^{[5] .}$ A ecomonia do município de Cacoal é movida principalmente pelas grandes indústrias do setor madeireiro, agropecuário e comércio.

\section{2 - Levantamento qualitativo e quantitativo das árvores}

\section{Avaliação de Árvore:}

Foram avaliadas as características:

- Danos causados a calçadas: comportamento das raízes em relação ao calçamento foi avaliado visualmente, considerando presentes ou ausentes.

- Informações sobre a fenologia (floração, frutificação e mudança foliar) das espécies foram levantadas através de revisão de literatura.

- Plantio: Quanto ao local onde a árvore foi plantada foi avaliado em campo o afastamento das garagens residenciais e esquinas através de mensuração e presença de fiação sobre a árvore analisada.

- Características das espécies: analisou-se o porte da espécie classificando como pequena espécie com ate $5 \mathrm{~m}$ de altura, médio de 5 a $8 \mathrm{~m}$ de altura e grande acima de $8 \mathrm{~m}$ de altura. Os dados foram anotados em uma planilha de campo e conferido com as informações contidas na literatura, já que a maioria das arvores a altura real estava influenciada pela poda freqüente.

- A avaliação da árvore e sua localização foram medida com fita métrica a distancias da arvore em relações as esquinas, garagem residenciais e postos de luminação o local estes dados foram devidamente anotada numa caderneta de campo e depois foi tabulada gerando um banco de dados e confrontados com as normas técnicas de arborização sugeridas pelo manual de arborização da CEMIG (2002).

\section{3 - Identificação botânica}

O sistema utilizado na identificação das árvores o material botânico foi através de metodologia usual taxonômica e consulta bibliografia especializada. O processo de identificação resultou na analise das características morfológicas das espécies de acordo com o sistema de classificação APG II (2003). As espécies foram fotografadas para facilitar a identificação e compreensão dos resultados do trabalho, assim como, proporcionar uma melhor visualização dos resultados por pessoas da comunidade local que não possuem conhecimento científico sobre as espécies.

\section{4 - Amostragem}


O sistema de amostragem adotado foi o método aleatório onde em cada bairro selecionado foram sorteadas $20 \%$ das suas ruas e avenidas, sendo estas avaliadas por inteiro.

Foram escolhidos os bairros que correspondem ao centro geográfico da cidade, pois os bairros da periferia não apresentam arborização. Os Bairros trabalhados foram os seguintes: Novo Cacoal, Novo Horizonte, Jardim Clodoaldo, Princesa Izabel, e o centro da cidade, totalizando 14 ruas e 12 avenidas.

\section{5 - Descrição das espécies encontradas:}

A descrição das espécies foi realizada com base na literatura especializada sobre o assunto e coleta de dados em campo. Foram fotografadas as espécies existentes e resumidamente descreveu-se cada uma, desde o porte, propagação e potencial ornamental.

\section{RESULTADOS E DISCUSSÕES}

Os resultados do processo de amostragem da vegetação urbana de Cacoal/RO teve como resultado 20 famílias botânicas distribuídas em 45 espécies, como pode ser observado na tabela 01 e Figura 02.

TABELA 01: Numero de espécie por família encontradas no levantamento florístico no município de Cacoal /RO

\begin{tabular}{lc}
\hline FAMÍLIA & NÚMERO DE ESPÉCIES \\
\hline Leguminoseae & 9 \\
Palmaceae & 7 \\
Anacardiaceae & 4 \\
Myrtaceae & 4 \\
Sterculiaceae & 3 \\
Bignoniaceae & 2 \\
Cupressaceae & 2 \\
Moraceae & 2 \\
Nictagenaceae & 1 \\
Anonaceae & 1 \\
Bombacaceae & 1 \\
Chrysobalanaceae & 1 \\
Cicadaceae & 1 \\
Combretaceae & 1 \\
Lauraceae & 1 \\
Lihraceae & 1 \\
Malpighiaceae & 1 \\
Malvaceae & 1 \\
Rhamnaceae & 1 \\
\hline
\end{tabular}




\begin{tabular}{lc}
\hline Rutaceae & 1 \\
\hline TOTAL & 45 \\
\hline
\end{tabular}

A família com maior numero de espécie foi Leguminoseae, 9 indivíduos, sendo que a maioria das famílias apresentaram 1 espécie, como pode ser observado na tabela 01 e figura 01

Apesar da família Leguminoseae ser a com maior número de espécies levantadas, não predomina na maioria dos indivíduos arbóreos presentes nos logradouros, sendo que dos 1479 indivíduos arbóreos levantados, 76,61\% (1151 indivíduos) encontram-se nas famílias Chrysobalanaceae (oiti)386 e Moraceae (fícus), 765 como pode ser observado na tabela 02.

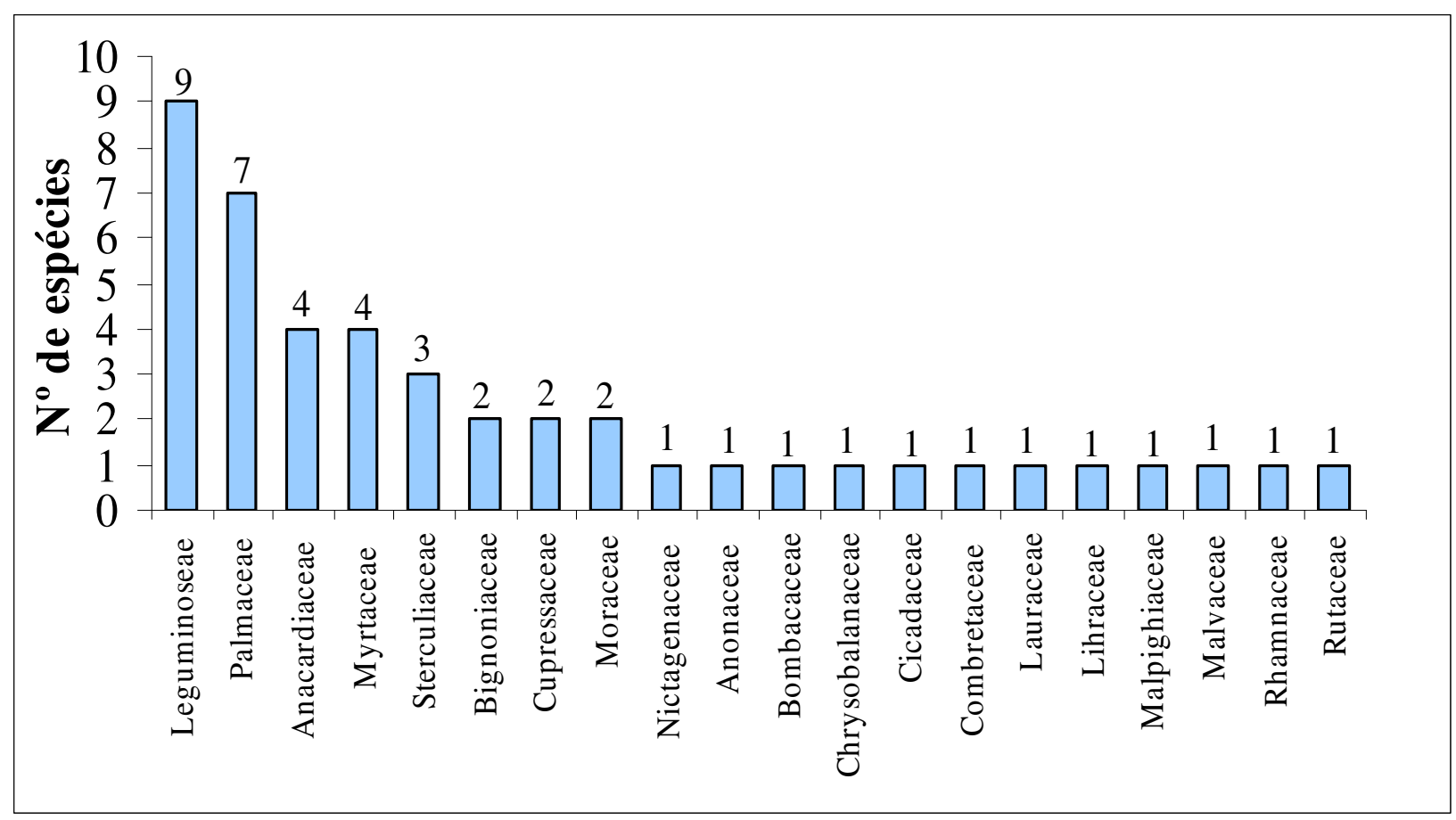

FIGURA 02: Famílias botânicas encontradas no diagnóstico da arborização urbana e os respectivos números de espécies.

A tabela 02 apresenta o número de indivíduos arbóreos por espécie e seus respectivos nomes vulgares, onde pode se observar à concentração dos indivíduos arbóreos nas espécies Ficus benjamina, Liconia tomentosa e Senna spectabilsi, com 80,18\% dos indivíduos.

A Maioria desta espécies estão causando dando nas calçadas, tendo cantato direto com a rede de elétrica, pondo em risco a vida humana durante a poda ou uma descarga 
elétrica durante chuvas, obstruindo a visão dos condutores de veículos, devido ter sido plantadas em local inadequado para o porte destas espécies.

Para Lima (1995) a diversificação das espécies deve ser respeitada contribuindo para a melhoria da estética do ambiente e redução de ataques de pragas.

TABELA 02: Relação de espécies levantadas com seus respectivos nomes vulgares, nomes científicos e número de indivíduos amostrados no diagnóstico da vegetação urbana no município de Cacoal / RO. 


\begin{tabular}{|c|c|c|}
\hline Fícus & Fícus benjamina & 765 \\
\hline Oiti & Liconia tomentosa & 386 \\
\hline São-joão & Senna spectabilis & 53 \\
\hline Mangueira & Mangifera indica & 29 \\
\hline Jambo vermelho & Eugenia malaccensis & 28 \\
\hline Sibipiruna & Caesalpinia peltophoroides & 25 \\
\hline Monguba & Pachira aquatica & 20 \\
\hline Murta & Murraya exotica & 19 \\
\hline Híbisco & Hibiscus rosa-sinensis & 15 \\
\hline Palmeira-imperial & Roystonea oleracea & 15 \\
\hline Palmeira-rabo-de-peixe & Caryota mitis & 15 \\
\hline Açaí & Euterpe oleracea & 15 \\
\hline Chapéu-de-sol & Terminalia catappa & 10 \\
\hline Pupunha & Bactris gasipaes & 9 \\
\hline Árvore-chinesa & Thuja orientalis & 8 \\
\hline Goiaba & Psidium guajava & 6 \\
\hline Palmeira - samambaia & Cycas circinalis & 5 \\
\hline Coco & Cocos nucifera & 5 \\
\hline Pata-de-vaca & Bauhinia variegata & 4 \\
\hline Cássia imperial & Cássia fistula & 4 \\
\hline Jaca & Artocarpus heterophyllus & 3 \\
\hline Palmeira-ana & Sabal minor & 2 \\
\hline Cajá-mirin & Spondia lutea & 2 \\
\hline Cacau & Theobroma cacao & 2 \\
\hline Cupuaçu-verdadeiro & Theobroma grandiflorum & 2 \\
\hline Cajueiro & Anacardium occidentale & 2 \\
\hline Jambolão & Eugenia jambolana & 2 \\
\hline Abacate & Persea americana & 2 \\
\hline Ingá-branco & Inga laurina & 2 \\
\hline Aroeira-salsa & Schinus molle & 2 \\
\hline Acerola & Malpighia glabra & 1 \\
\hline Cássia javanesa & Cassia nodosa & 1 \\
\hline Uva-japonesa & Hovenia dulcis & 1 \\
\hline Espatódia & Spathodea campanulata & 1 \\
\hline Graviola & Annona muricata & 1 \\
\hline Laranja & Citrus sinensis & 1 \\
\hline Ingá-cipó & Inga edulis & 1 \\
\hline Jaboticaba & Myrciaria cauliflora & 1 \\
\hline Dólar-de-prata & Eucalyptus cenerea & 1 \\
\hline Tamarindo & Tamarindus indica & 1 \\
\hline Extremosa & Lagerstroemia indica & 1 \\
\hline Primavera & Bougainvellea spectabilis & 1 \\
\hline Flamboianzinho & Caesalpinia pulcherrima & 1 \\
\hline Figueira-mata-pau & Fícus guaranitica & 1 \\
\hline Total & & 1.479 \\
\hline
\end{tabular}

Devido á grande carência de informações na literatura sobre porte e época de floração, realizou-se a descrição das espécies levantadas baseando-se em dados contidos na literatura de forma a gerar um material didático e técnico-científico, que possa contribuir para a orientação da readequação da arborização urbana dos bairros de Cacoal e, até mesmo, contribua para a arborização de outras cidades da região, já que não existe um 
consenso sobre as espécies mais indicadas para a arborização das cidades da região norte.

\section{1-Relação das Espécies Árboreas Encontradas No levantamento da Arborização urbana do Município de Cacoal-Ro}

As informações sobre as espécies levantadas foram descritas por nome cientifico, nome popular, família, origem, porte, tipo de copa, época de floração, propagação e o potencial ornamental de cada espécies como mostra a relação no quadro abaixo.

Descrições das Espécies Árboreas Encontradas No Diagnóstico Da Vegetação Utilizada Para Arborização, identificadas de acordo com o sistema de classificação APG II (2003)

Nome Científico: Licania tomentosa.

Nome popular: Oiti

Família: Chrysobalanaceae

Origem: Nativa

Porte: 8 a $15 \mathrm{~m}$ de altura

Copa: arredondada e frondosa

Fenologia: de julho a setembro

Frutificação: de janeiro a março

Propagação: Sementes.

Potencial ornamental: utilizada na arborização de praças, jardins, ruas e avenidas, ( LORENZI, 2002).

Nome Científico: Hovenia dulcis

Nome popular: Uva-japonesa

Família: Rhamnaceae

Origem: Exótica

Porte: $6-10 \mathrm{~m}$

Copa: globosa

Fenologia: primavera

Frutificação: entre março e outubro.

Propagação: semente.

Potencial ornamental: é usada em jardim e na recuperaçăo de áreas

degradadas,(RIBEIRO,2007).

Nome Científico: Hibiscus rosa sinensis
Nome popular: Híbisco
Família: Malvaceae
Origem: Exótica
Porte: 4 m
Copa: arredondada
Floração: O ano todo.
Frutificação:
Propagação: estaquia e semente
Potencial ornamental: utilizada na arborização
de praças, jardins, ruas e avenidas, (MATTER,
2007).
Nome Científico: Cassia nodosa
Nome popular: Cássia javanesa
Família: Leguminoseae
Origem: Exótica
Porte: 10 m
Copa: arredondada
Floração: dezembro a fevereiro.
Frutificação: setembro a novembro.
Propagação: Semente
Potencial ornamental: é usada em jardim e
na recuperaçăo de áreas
degradadas,(MATTER,2007).

Família: Malvaceae

Origem: Exótica

Porte: $4 \mathrm{~m}$

Copa: arredondada

Floração: $O$ ano todo.

Frutificação:

Propagação: estaquia e semente

Potencial ornamental: utilizada na arborização

de praças, jardins, ruas e avenidas, (MATTER, 2007) 


\begin{tabular}{|c|c|}
\hline $\begin{array}{l}\text { Nome Científico: Caesalpinia peltophoroides } \\
\text { Nome popular: Sibipiruna } \\
\text { Família: Leguminoseae } \\
\text { Origem: Nativa } \\
\text { Porte: atinge até } 18 \text { metros de altura } \\
\text { Copa: arredondada } \\
\text { Floração: setembro a novembro. } \\
\text { Frutificação: de julho a agosto. } \\
\text { Propagação: Semente. } \\
\text { Podas: não são necessárias. } \\
\text { Potencial ornamental: empregada com } \\
\text { sucesso na arborização de praça e parques, } \\
\text { (LORENZl, 2002). }\end{array}$ & $\begin{array}{l}\text { Nome Científico: Senna spectabilis } \\
\text { Nome popular: São-joão } \\
\text { Família: Leguminoseae } \\
\text { Origem: Nativa } \\
\text { Porte: de } 6 \text { a } 9 \text { m de altura. } \\
\text { Copa: arredondada } \\
\text { Floração: dezembro a abril. } \\
\text { Frutificação: de agosto a setembro. } \\
\text { Propagação: Semente. } \\
\text { Potencial ornamental: A árvore é empregada } \\
\text { com sucesso no paisagismo em geral ideal } \\
\text { para arborização de ruas, (LORENZI, 2002). }\end{array}$ \\
\hline $\begin{array}{l}\text { Nome Científico: Bauhinia variegata } \\
\text { Nome popular: Pata -de-vaca } \\
\text { Família: Leguminoseae } \\
\text { Origem: Exótica } \\
\text { Porte: } 4 \text { - } 8 \mathrm{~m} \\
\text { Copa: arredondada } \\
\text { Floração: de julho a outubro. } \\
\text { Frutificação: de outubro a dezembro. } \\
\text { Propagação: sementes. } \\
\text { Potencial ornamental: empregada com } \\
\text { sucesso na arborização de ruas e avenida, } \\
\text { praça e parques, (MATTER,2007) }\end{array}$ & $\begin{array}{l}\text { Nome Científico: Caesalpinia pulcherrima } \\
\text { Nome popular: Flamboianzinho } \\
\text { Família: Lguminoseae } \\
\text { Origem: Exótica } \\
\text { Porte: de } 3 \text { a } 4 \mathrm{~m} \\
\text { Copa: arredondada. } \\
\text { Floração: Setembro a maio. } \\
\text { Frutificação: } \\
\text { Propagação: sementes } \\
\text { Potencial ornamental: empregada com } \\
\text { sucesso na arborização de ruas e jardins, } \\
\text { (MATTER, 2007) }\end{array}$ \\
\hline $\begin{array}{l}\text { Nome Científico: Murraya exótica } \\
\text { Nome popular: Murta } \\
\text { Família: Rutaceae } \\
\text { Origem: Exótica } \\
\text { Porte: de } 3 \text { a } 5 \text { m } \\
\text { Copa: arredondadas } \\
\text { Floração: Outubro a Janeiro } \\
\text { Frutificação: } \\
\text { Propagação: sementes } \\
\text { Potencial ornamental: empregada com } \\
\text { sucesso na arborização de ruas, avenida e } \\
\text { jardins, (MATTER, 2007). }\end{array}$ & $\begin{array}{l}\text { Nome Científico: Lagerstroemia indica } \\
\text { Nome popular: Extremosa } \\
\text { Família: Lihraceae } \\
\text { Origem: Exótica } \\
\text { Porte: de } 4 \text { a } 6 \text { m } \\
\text { Copa: arredondada. } \\
\text { Floração: Outubro a março } \\
\text { Frutificação: } \\
\text { Propagação: sementes e estaca } \\
\text { Potencial ornamental: empregada com } \\
\text { sucesso na arborização de ruas e jardins, } \\
\text { (LORENZI, 2001). }\end{array}$ \\
\hline $\begin{array}{l}\text { Nome Científico: Cassia fistula } \\
\text { Nome popular: Cássia imperial } \\
\text { Família: Leguminoseae } \\
\text { Origem: Exotica } \\
\text { Porte: de } 7 \text { a } 9 \mathrm{~m} \\
\text { Copa: arredondada. } \\
\text { Floração: dezembro / Abril } \\
\text { Frutificação: março a abril } \\
\text { Propagação: sementes } \\
\text { Potencial ornamental: empregada com } \\
\text { sucesso na arborização de ruas e jardins, } \\
\text { (MATTER, 2007). }\end{array}$ & $\begin{array}{l}\text { Nome Científico: Bougainvellea spectabilis } \\
\text { Nome popular: Primavera } \\
\text { Família: Nictagenaceae } \\
\text { Origem: Exótica } \\
\text { Porte: ate } 5 \mathrm{~m} \\
\text { Copa: arredondada. } \\
\text { Floração: quase o ano inteiro } \\
\text { Frutificação: } \\
\text { Propagação: estaquia de galho } \\
\text { Potencial ornamental: empregada com } \\
\text { sucesso na arborização de ruas e jardins, } \\
\text { (LORENZI, 2001). }\end{array}$ \\
\hline
\end{tabular}




\begin{tabular}{|c|c|}
\hline $\begin{array}{l}\text { Nome Científico: Spondias lutea. } \\
\text { Nome popular: Cajá-mrim } \\
\text { Família: Anacardiaceae } \\
\text { Origem: Exótica } \\
\text { Porte: } 12 \text { a } 20 \text { m de altura } \\
\text { Copa: arredondada } \\
\text { Fenologia: Novembro a janeiro } \\
\text { Frutificação: Maio a junho } \\
\text { Propagação: Sementes } \\
\text { Potencial ornamental: utilizada para } \\
\text { recuperação de área degradada, (RIBEIRO, } \\
\text { 2007). }\end{array}$ & $\begin{array}{l}\text { Nome Cientifico: Terminalia catappa } \\
\text { Nome popular: Chapéu-de-sol } \\
\text { Família: Combretaceae } \\
\text { Origem: Exótica } \\
\text { Porte: } 10 \text { m de Altura } \\
\text { Copa: irregular } \\
\text { Fenologia: de setembro a novembro. } \\
\text { Frutificação: de julho a agosto. } \\
\text { Propagação: semente } \\
\text { Potencial ornamental: espécie recomenda } \\
\text { somente para arborização de parques e praça, } \\
\text { (RIBEIRO,2007). }\end{array}$ \\
\hline $\begin{array}{l}\text { Nome Científico: Myrciaria cauliflora } \\
\text { Nome popular: Jaboticaba } \\
\text { Família: Myrtaceae } \\
\text { Origem: Nativa } \\
\text { Porte: de } 10 \text { a } 15 \mathrm{~m} \\
\text { Copa: arredondada. } \\
\text { Floração: Junho a agosto e novembro a } \\
\text { dezembro } \\
\text { Frutificação: agosto a setembro e janeiro } \\
\text { Propagação: sementes. } \\
\text { Potencial ornamental: È empregada no } \\
\text { paisagismo em geral, (LORENZI, 2002). }\end{array}$ & $\begin{array}{l}\text { Nome Científico: Cycas circinalis } \\
\text { Nome popular: Palmeira - samambaia. } \\
\text { Família: Cycadaceae } \\
\text { Origem: Exótica } \\
\text { Porte: de } 3 \text { a } 5 \mathrm{~m} \\
\text { Copa: pendente } \\
\text { Floração: outono e inverno } \\
\text { Frutificação: primavera } \\
\text { Propagação: sementes. } \\
\text { Potencial ornamental: empregada com } \\
\text { sucesso na arborização de ruas, avenidas e } \\
\text { jardins, (LORENZI, 2004.). }\end{array}$ \\
\hline $\begin{array}{l}\text { Nome Científico: Sabal minor } \\
\text { Nome popular: Palmeira - ana } \\
\text { Família: Palmaceae } \\
\text { Origem: Exótica } \\
\text { Porte: ate } 1,80 \mathrm{~m} \\
\text { Copa: pendente } \\
\text { Floração: } \\
\text { Frutificação: inverno } \\
\text { Propagação: sementes. } \\
\text { Potencial ornamental: empregada com } \\
\text { sucesso na arborização de ruas, avenidas e } \\
\text { jardins,(LORENZI, 2004.). }\end{array}$ & $\begin{array}{l}\text { Nome Científico: Schinus molle } \\
\text { Nome popular: Aroeira -salsa } \\
\text { Família: Anacardiaceae } \\
\text { Origem: Nativa } \\
\text { Porte: Pode chegar ate } 20 \text { m de altura } \\
\text { Copa: Pendente } \\
\text { Floração: de setembro a novembro } \\
\text { Frutificação: de dezembro a março } \\
\text { Propagação: semente. } \\
\text { Potencial ornamental: cultivada como } \\
\text { ornamental tanto em sua região de ocorrência } \\
\text { natural quanto fora em jardins e parques, } \\
\text { (LORENZI, 2002). }\end{array}$ \\
\hline $\begin{array}{l}\text { Nome Científico: Ficus guaranitica } \\
\text { Nome popular: figueira-mata-pau } \\
\text { Família: Moraceae } \\
\text { Origem: Nativa } \\
\text { Porte: } 10 \text { a } 20 \mathrm{~m} \text { de altura } \\
\text { Copa: arredondada, frondosa } \\
\text { Fenologia: setembro a outubro } \\
\text { Frutificação: dezembro a janeiro } \\
\text { Propagação: Sementes. } \\
\text { Potencial ornamental: utilizada na arborização } \\
\text { rural, praças grandes e jardins, (LORENZI, } \\
\text { 2002). }\end{array}$ & $\begin{array}{l}\text { Nome Científico: Spathodea campanulata } \\
\text { Nome popular: Espatódia } \\
\text { Família: Bignoniaceae } \\
\text { Origem: Exótica } \\
\text { Porte: até } 25 m \\
\text { Copa: arredondada } 6 \mathrm{~m} . \\
\text { Floração: de abril a maio. } \\
\text { Frutificação: de julho a setembro. } \\
\text { Propagação: semente. } \\
\text { Potencial ornamental: na abroização de } \\
\text { parques, jardins e praça, (MATTER,2007) }\end{array}$ \\
\hline
\end{tabular}




Nome Científico: Pachira aquatica
Nome popular: Monguba
Família: Bombacaceae
Origem: Nativa
Porte: de 6 a $14 \mathrm{~m}$
Copa: globosa
Floração: Setembro a novembro
Frutificação: de abril a junho
Propagação: sementes
Potencial ornamental: produz ótima sombra,
muita utilizada na arborização urbana em
muitas cidades brasileira, (LORENZI,2002).

Nome Científico: Anacardium occidentale Nome popular: Cajueiro

Família: Anacardiaceae

Origem: Nativa

Porte: de 5 a $10 \mathrm{~m}$

Copa: Arredondada.

Floração: de junho a novembro

Frutificação: Setembro a janeiro

Propagação: Sementes.

Potencial ornamental: Não indicada para paisagismo urbano, ( LORENZI,2002).

Nome Científico: Roystonea oleracea

Nome popular: Palmeira - imperial

Família: Palmaceae

Origem: Exótica

Porte: de 18 a $40 \mathrm{~m}$

Copa: pendente

Floração:

Frutificação: dezembro a fevereiro

Propagação: sementes

Potencial ornamental: empregada com

sucesso na arborização de ruas, avenidas,

praças e jardins,

(LORENZI, 2004).

Nome Científico: Psidium guajava

Nome popular: Goiaba

Família: Myrtaceae

Origem: Nativa

Porte: de 3 a $6 \mathrm{~m}$

Copa: arredondada.

Floração: Setembro a novembro

Frutificação: Dezembro a março

Propagação: sementes

Potencial ornamental: Somente para

recomposição de área degradada de

preservação,

(LORENZI, 2002).
Nome Científico: Euterpe oleracea

Nome popular: Palmeira - açaí.

Família: Palmaceae

Origem: Nativa

Porte: ate $20 \mathrm{~m}$

Copa: pendente

Floração: setembro a janeiro

Frutificação: outono

Propagação: sementes.

Potencial ornamental: empregada com sucesso na arborização de ruas, praça e jardins, (LORENZI, 2002).

Nome Científico: Caryota mitis

Nome popular: Palmeira-rabo-de-peixe

Família: Palmaceae

Origem: Exótica

Porte: ate $10 \mathrm{~m}$

Copa: pendente

Floração:

Frutificação:

Propagação: sementes e bulbos.

Potencial ornamental: empregada com

sucesso na arborização de ruas e jardins, (LORENZI, 2004).

Nome Científico: Theobrama cacao

Nome popular: Cacau - verdadeiro

Família: Sterculiaceae

Origem: Nativa

Porte: de 4 a 6 m

Copa: arredondada.

Floração: Dezembro a abril

Frutificação: Abril a setembro

Propagação: sementes.

Potencial ornamental: Não posui potencial

ornamental, (LORENZI, 2002).
Nome Científico: Inga laurina

Nome popular: Ingá-branco

Família: Leguminoseae

Origem: Nativa

Porte: de 10 a $20 \mathrm{~m}$

Copa: frondosa

Floração: Agosto a dezembro

Frutificação: Novembro a Fevereiro

Propagação: sementes.

Potencial ornamental: Produz ótima sombra sendo assim utilizada na arborização urbana, (LORENZI, 2002). 


\begin{tabular}{|c|c|}
\hline $\begin{array}{l}\text { Nome Científico: Theobroma grandiflorum } \\
\text { Nome popular: Cupuaçu-verdadeiro } \\
\text { Família: Sterculiaceae } \\
\text { Origem: Nativa } \\
\text { Porte: de } 4 \text { a } 8 \mathrm{~m} \text { (ate } 15 \mathrm{~m} \text { na mata alta) } \\
\text { Copa: piramidal } \\
\text { Floração: Setembro a novembro } \\
\text { Frutificação: Fevereiro a abril } \\
\text { Propagação: sementes } \\
\text { Potencial ornamental: recuperação de área } \\
\text { degradada,(LORENZI, 2002). }\end{array}$ & $\begin{array}{l}\text { Nome Científico: Syzygium malaccense } \\
\text { Nome popular: Jambo-vermelho } \\
\text { Família: Myrtaceae } \\
\text { Origem: Exótica } \\
\text { Porte: de } 12 \text { a } 15 \text { m de altura } \\
\text { Copa: densa de forma crônico-alongado. } \\
\text { Floração: Outubro a março } \\
\text { Frutificação: logo após a floração } \\
\text { Propagação: sementes } \\
\text { Potencial ornamental: planta pode ser usada } \\
\text { na arborização de praças, } \\
\text { parques,(RIBEIRO,2007). }\end{array}$ \\
\hline $\begin{array}{l}\text { Nome Científico: Inga edulis } \\
\text { Nome popular: Ingá - cipó } \\
\text { Família: Leguminoseae } \\
\text { Origem: Nativa } \\
\text { Porte: de } 6 \text { a } 25 \mathrm{~m} \\
\text { Copa: ampla e baixa } \\
\text { Floração: outubro ate janeiro } \\
\text { Frutificação: apartir do mês de maio } \\
\text { Propagação: sementes } \\
\text { Potencial ornamental: Espécie não } \\
\text { recomendada para arborização urbana, } \\
\text { (LORENZI, 2002). }\end{array}$ & $\begin{array}{l}\text { Nome Científico: Citrus sinensis } \\
\text { Nome popular: Laranja } \\
\text { Família: Rutaceae } \\
\text { Origem: Exótica } \\
\text { Porte: até } 6 \text { metros de altura } \\
\text { Copa: arredondada. } \\
\text { Floração: primavera e verão } \\
\text { Frutificação: verão } \\
\text { Propagação: sementes e enxertia. } \\
\text { Potencial ornamental: espécie não } \\
\text { recomenda para arborização, (RIBEIRO,2007). }\end{array}$ \\
\hline $\begin{array}{l}\text { Nome Científico: Eugenia jambolana } \\
\text { Nome popular: Jambolão } \\
\text { Família: Myrtaceae } \\
\text { Origem: Exótica } \\
\text { Porte: até } 20 \text { metros de altura } \\
\text { Copa: frondosa. } \\
\text { Floração: outono e inverno } \\
\text { Frutificação: } \\
\text { Propagação: sementes } \\
\text { Potencial ornamental: planta pode ser usada } \\
\text { na arborização de praças, parques, ao longo de } \\
\text { estradas, mata ciliar e como quebra-vento, } \\
\text { (RIBEIRO,2007). }\end{array}$ & $\begin{array}{l}\text { Nome Científico: Annona muricata } \\
\text { Nome popular: Graviola } \\
\text { Família: Annonaceae } \\
\text { Origem: Exótica } \\
\text { Porte: de } 4 \text { a } 6 \text { metros de altura } \\
\text { Copa: cônica } \\
\text { Floração: quase o ano inteiro } \\
\text { Frutificação: quase o ano inteiro } \\
\text { Propagação: sementes } \\
\text { Potencial ornamental: Espécie indicada para } \\
\text { o cultivo em jardins, (RIBEIRO,2007). }\end{array}$ \\
\hline $\begin{array}{l}\text { Nome Científico: Artocarpus heterophyllus } \\
\text { Nome comum: Jaca } \\
\text { Família: Moraceae } \\
\text { Origem: Exótica } \\
\text { Porte: atingir } 20 \text { metros de altura. } \\
\text { Copa: arredondada. } \\
\text { Floração; primavera e verão. } \\
\text { Frutificação: outono } \\
\text { Propagação: sementes. } \\
\text { Potencial ornamental: produz ótima sombra } \\
\text { porem não recomendada para arborização } \\
\text { devido os frutos ser muito grande, } \\
\text { (RIBEIRO,2007). }\end{array}$ & $\begin{array}{l}\text { Nome Científico: Malpighia glabra } \\
\text { Nome popular: Acerola } \\
\text { Família: Malpighiaceae } \\
\text { Origem: Exótica } \\
\text { Porte: de } 2 \text { a } 4 \text { metros } \\
\text { Copa: arredondada. } \\
\text { Floração: dezembro a fevereiro } \\
\text { Frutificação: logo após a floração } \\
\text { Propagação: sementes e enxertia } \\
\text { Potencial ornamental: espécie indicada para o } \\
\text { cultivo em jardins, (RIBEIRO,2007). }\end{array}$ \\
\hline
\end{tabular}




\begin{tabular}{|c|c|}
\hline $\begin{array}{l}\text { Nome Científico: Persea americana } \\
\text { Nome popular: Abacate } \\
\text { Família: Lauraceae } \\
\text { Origem: Exótica } \\
\text { Porte: até } 20 \text { m de altura } \\
\text { Copa: elíptica } \\
\text { Floração: setembro a novembro } \\
\text { Frutificação: quase o ano inteiro } \\
\text { Propagação: sementes } \\
\text { Potencial ornamental: espécie não indicada } \\
\text { para arborização porem cultivadas em jardins, } \\
\text { (RIBEIRO, 2007). }\end{array}$ & $\begin{array}{l}\text { Nome Científico: Tamarindus indica } \\
\text { Nome popular: Tamarindos } \\
\text { Família: Leguminoseae } \\
\text { Origem: Exótica } \\
\text { Porte: ate } 30 \mathrm{~m} \\
\text { Copa: globosa } \\
\text { Floração: dezembro a fevereiro } \\
\text { Frutificação: logo após a floração } \\
\text { Propagação: sementes. } \\
\text { Potencial ornamental: empregada com } \\
\text { sucesso na arborização de ruas e jardins, } \\
\text { (RIBEIRO, 2007). }\end{array}$ \\
\hline $\begin{array}{l}\text { Nome Científico: Eucalyptus cenerea } \\
\text { Nome popular: Eucalipto } \\
\text { Família: Myrtaceae } \\
\text { Origem: Exótica } \\
\text { Porte: atingir } 40 \text { metros de altura } \\
\text { Copa: colunar } \\
\text { Floração: primavera e verão } \\
\text { Frutificação: ? } \\
\text { Propagação: sementes } \\
\text { Potencial ornamental: espécie não } \\
\text { recomendada para o plantio em arborização, } \\
\text { (MATTER,2007). }\end{array}$ & $\begin{array}{l}\text { Nome Científico: Cocos nucifera } \\
\text { Nome popular: Coco } \\
\text { Família: Palmeae } \\
\text { Origem: Nativa } \\
\text { Porte: de } 10 \text { a } 20 \text { m de altura } \\
\text { Copa: Pendente } \\
\text { Floração: janeiro a abril } \\
\text { Frutificação: dezembro a fevereiro } \\
\text { Propagação: sementes ( fruto). } \\
\text { Potencial ornamental: espécie cultiva no } \\
\text { paisagismo em todas as cidades da costa } \\
\text { atlântica,(LORENZI, 2002). }\end{array}$ \\
\hline $\begin{array}{l}\text { Nome Científico: Ficus benjamina } \\
\text { Nome popular: Figueira-benjamina } \\
\text { Família: Moraceae } \\
\text { Origem: Exótica } \\
\text { Porte: Até } 10 \mathrm{~m} \text { de altura } \\
\text { Copa: arredondada. } \\
\text { Floração: } \\
\text { Frutificação: outono } \\
\text { Propagação: sementes. } \\
\text { Potencial ornamental: empregada com } \\
\text { sucesso na arborização de ruas, avenidas, } \\
\text { praça e jardins, } \\
\text { (MATTER,2007). }\end{array}$ & $\begin{array}{l}\text { Nome Científico: Mangifera indica } \\
\text { Nome popular: Manga, mangueira. } \\
\text { Família: Anacardiaceae } \\
\text { Origem: Exótica } \\
\text { Porte: de } 10 \text { a } 30 \text { m de altura } \\
\text { Copa: densa frondosa } \\
\text { Floração: de junho a agosto } \\
\text { Frutificação: setembro a janeiro } \\
\text { Propagação: sementes. } \\
\text { Potencial ornamental: espécie não indicada } \\
\text { para arborização, (RIBEIRO, 2007). }\end{array}$ \\
\hline \multicolumn{2}{|c|}{$\begin{array}{l}\text { Nome Científico: Thuya orientalis } \\
\text { Nome popular: Àrvore-chinesa } \\
\text { Família: Cupressaceae } \\
\text { Origem: Exótica } \\
\text { Porte: até } 12 \text { m de altura } \\
\text { Copa: crônica } \\
\text { Floração; } \\
\text { Frutificação: } \\
\text { Propagação: Estaquia. } \\
\text { Potencial ornamental: empregada com sucesso na arborização de ruas, praça avenidas e } \\
\text { jardins, (LORENZI, 2001). }\end{array}$} \\
\hline
\end{tabular}

O presente trabalho teve também como objetivo analisar as condições da arborização urbana quanto aos aspectos: disposição das árvores sob fios de energia (4) (P) 
elétrica, danos a calçadas, distância das árvores quanto aos postes de iluminação, entrada de garagem e esquinas.

Estas características foram selecionadas por serem recomendações técnicas de manuais de arborização urbana. Para o trabalho em específico, adotamos o Manual da CEMIG/IEF (2001), o qual adota estes critérios com objetivos de reduzir acidentes e danos materiais causados pela arborização urbana inadequada. Dentre os aspectos levantados a presente pesquisa apresentou os seguintes resultados:

\subsection{Disposição das árvores sob fios de energia elétrica}

Quanto à disposição das árvores avaliadas plantadas sob a fiação elétrica foi analisada a sua interferência na rede elétrica (figura 04). Como pode ser observado na figura 03, das 1.237 árvores plantadas sob fiação elétrica 56,10\% interferem na fiação, ou seja, durante o levantamento $56,10 \%$ das árvores avaliadas tocavam a fiação pondo em risco a vida humana, seja durante a poda ou durante as chuvas (por uma descarga elétrica).

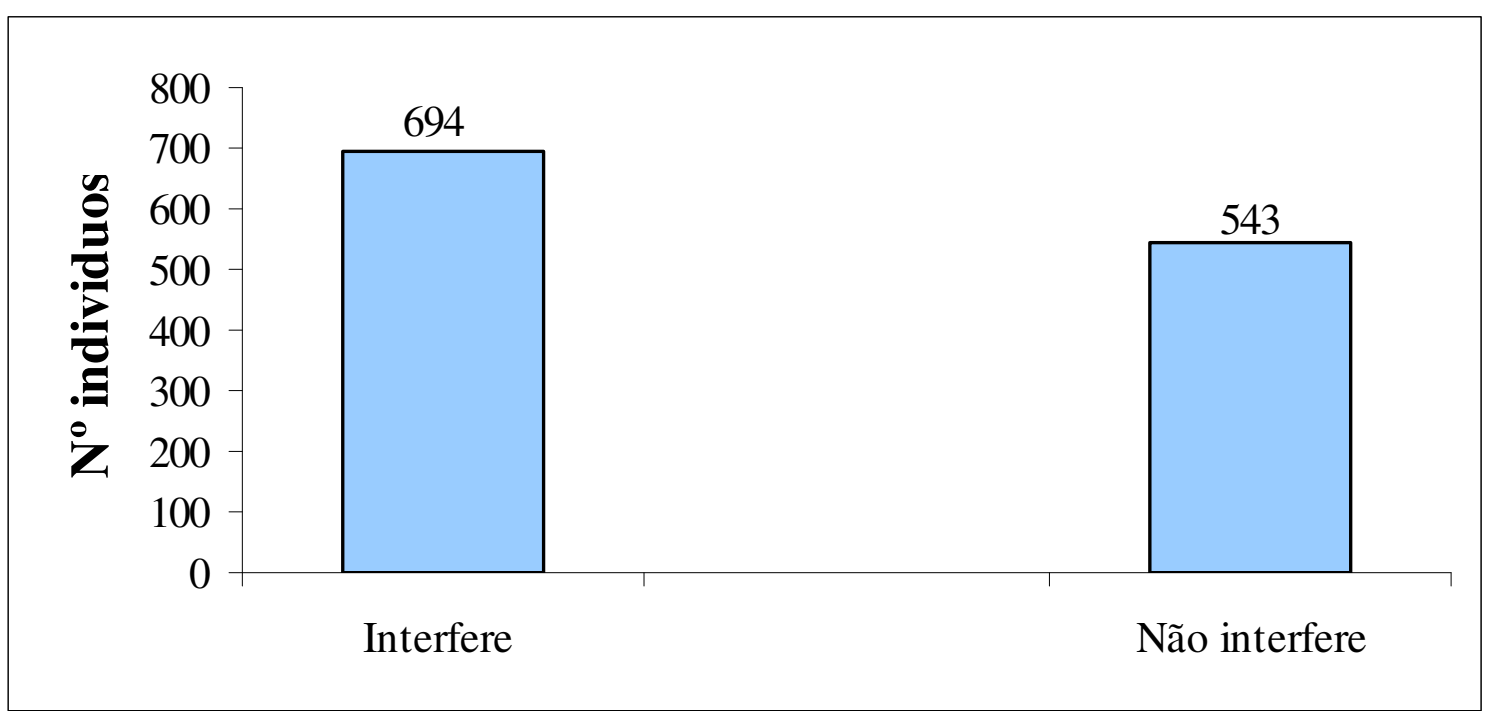

FIGURA 03: Avaliação do número de árvores plantadas sob fiação e seu grau de interferência na fiação. 


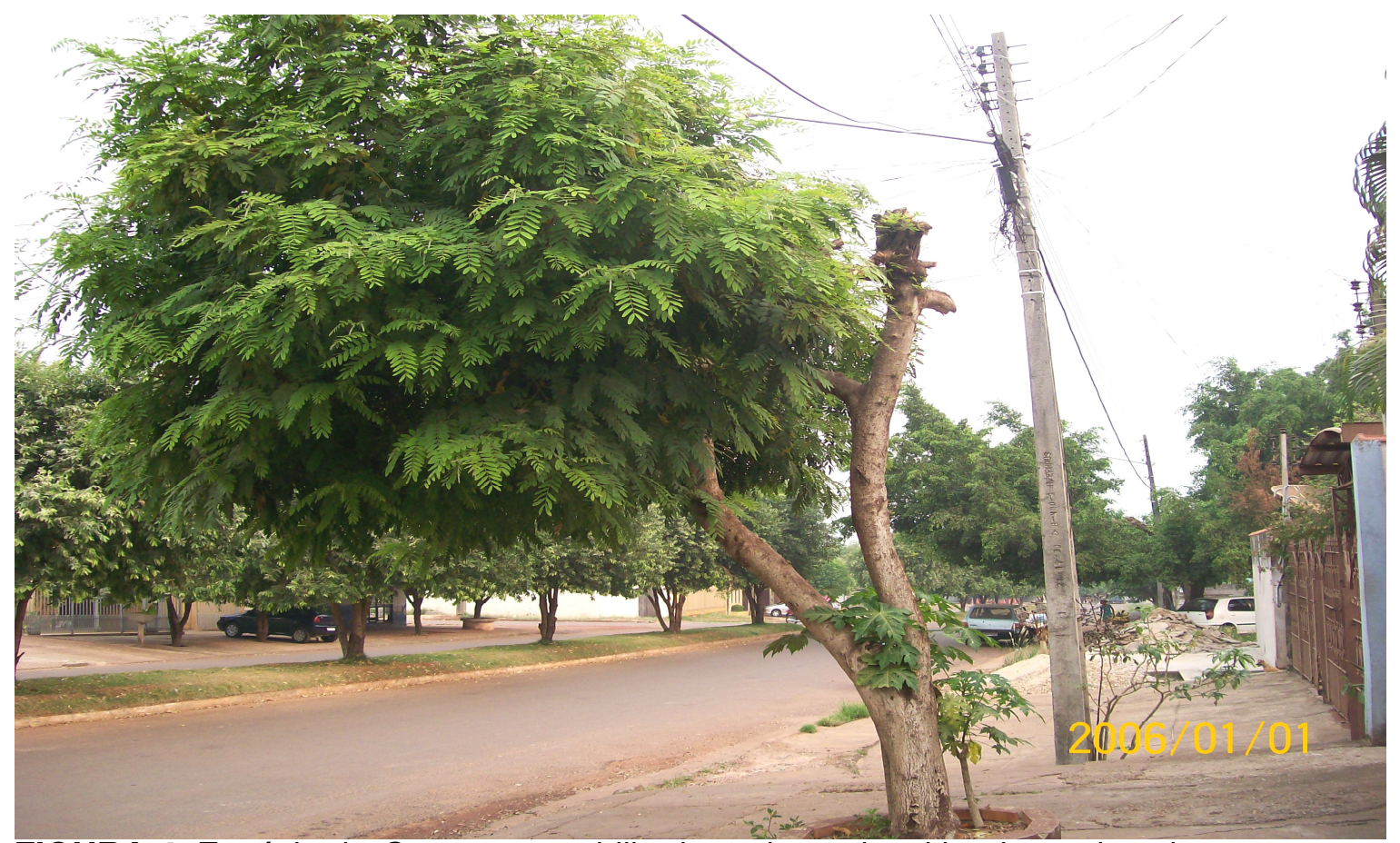

FIGURA-4. Espécie de Senna spectabilis plantada em local inadequado cuja a copa interferindo na fiação,(SILVA, J.L. 2006).

\subsection{Danos causados às calçadas.}

Quanto ao número de árvores levantadas pode-se observar que 60,79\% das árvores avaliadas causaram algum tipo de dano às calçadas (Figura 5 e figura 6).

Este grande número de árvores causando danos às calçadas como se observou no figura 06 é reflexo do número de plantas de grande porte plantadas e também da escolha da espécie que apresenta como característica um grande número de raízes superficiais, como é o caso do Ficus benjamina.

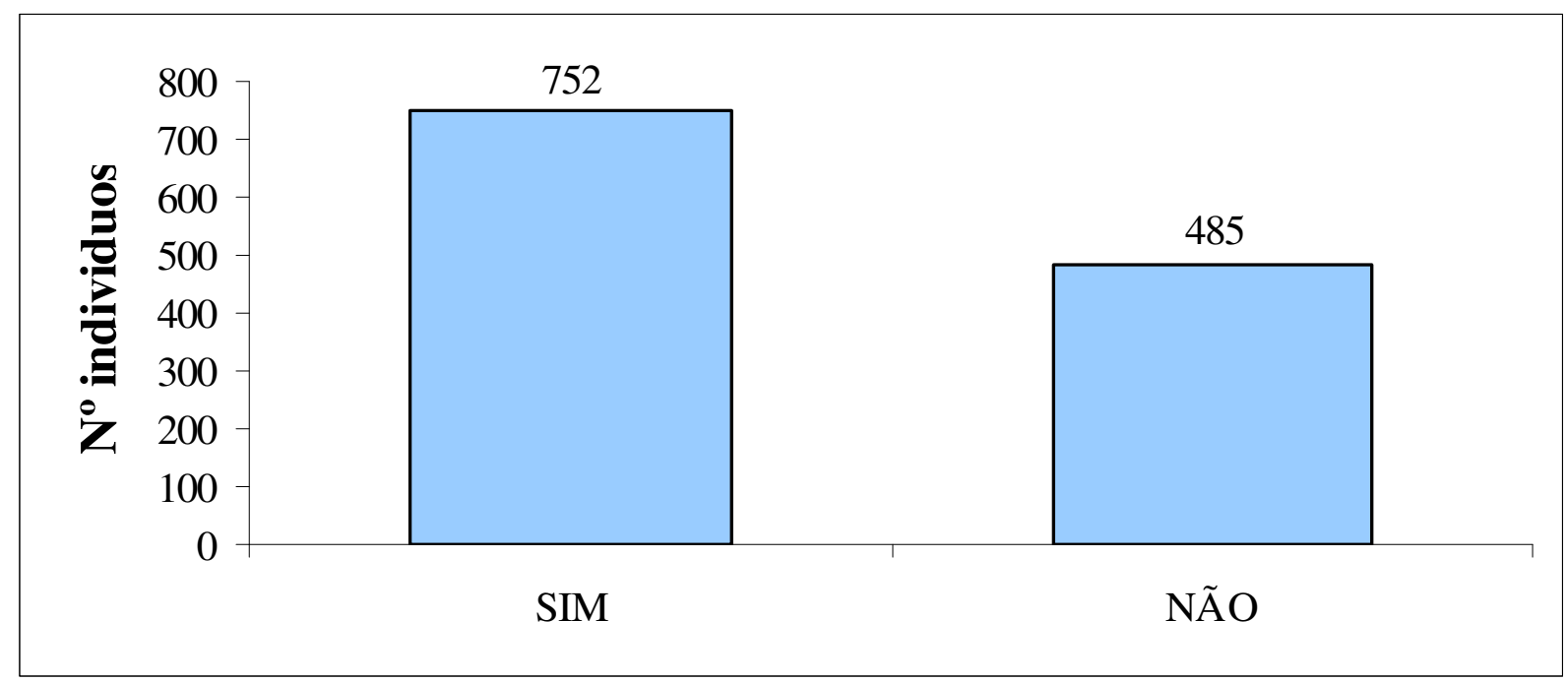

FIGURA 05 Avaliação do número de árvores danificando o calçamento 


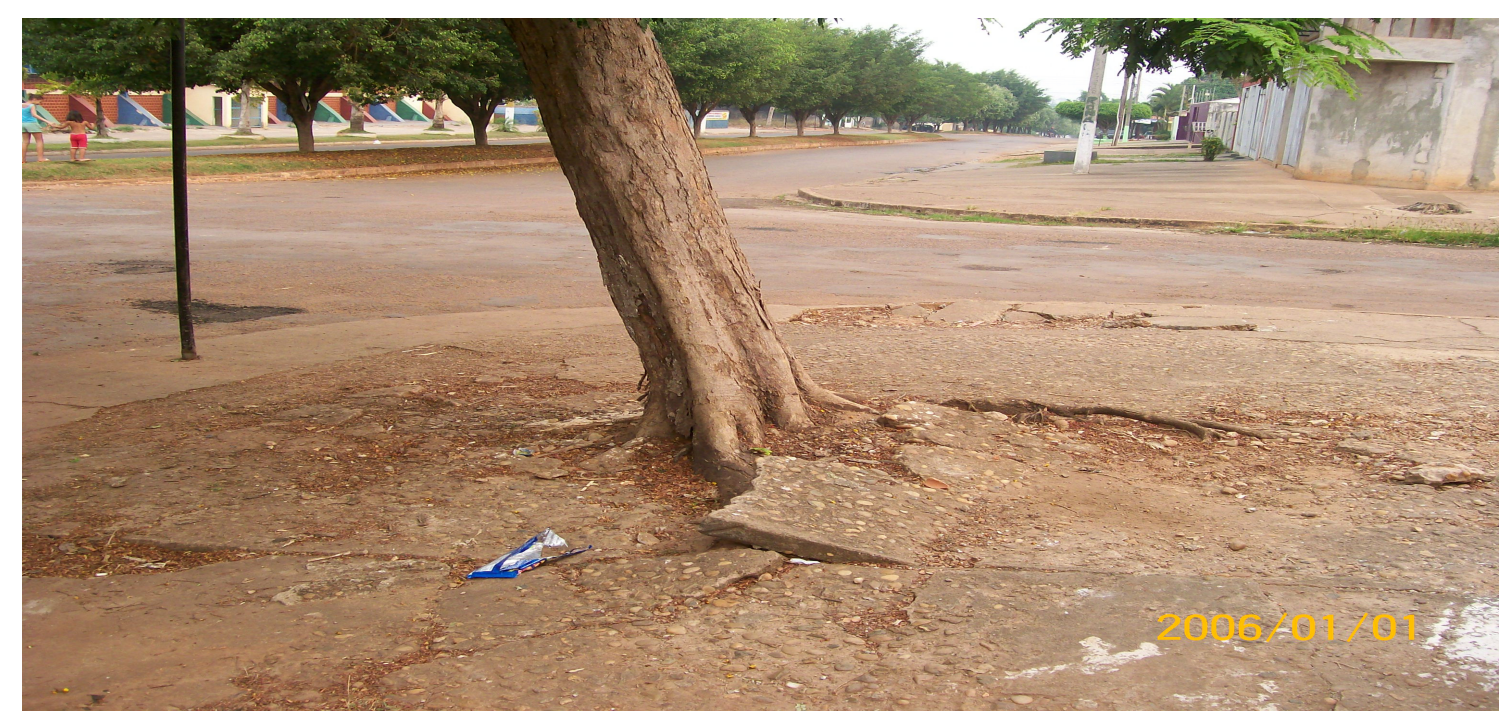

FIGURA 6-Espécie Caesalpinia peltophoroides, danificando as calçadas das ruas e avenidas de Cacoal, (SILVA, J.L. 2006).

\subsection{Disposição das árvores quanto às garagens residenciais e postes de iluminação}

A tabela 03 mostra a disposição das árvores quanto a garagens e postes de iluminação, critérios técnicos estes que segundo o manual de arborização da CEMIG/IEF (2002), levam em conta a segurança pública, pois árvores a menos de 2 metros da garagem dificultam a visibilidade do motorista no momento de estacionar seus veículos e quanto às árvores plantadas menos de 5 metros da esquina, segundo o mesmo manual, obstrui a visão do condutor do veículo deixando em condições vulneráveis a acidentes.

TABELA 03: Avaliação da disposição das árvores quanto à garagem e poste de iluminação

\begin{tabular}{lc}
\hline Distância da garagem à árvore na calçado & Número de árvores \\
\hline Mais de $2 \mathrm{~m}$ & 515 \\
& 722 \\
\hline Menos de $2 \mathrm{~m}$ & 1105 \\
\hline Distância da garagem á árvore na calçada, esquina e posto de iluminação & \\
Menos de $5 \mathrm{~m}$ & 131 \\
\hline
\end{tabular}

A tabela 03 mostra que 722 árvores estão plantadas irregularmente quando se toma como base à distância entre estas e as garagens e 131 árvores quanto à distância destas as esquinas e postos de iluminação.

\subsection{Classificação das espécies quanto ao porte}


A figura 07 mostra a classificação quanto ao porte dos indivíduos arbóreos levantados, mostrando a predominância de indivíduos de grande porte, com 95\% dos indivíduos amostrados, explicando assim, o grande número de indivíduos causando danos nas calçadas obstruindo a visão dos condutores de veículos e interferindo na rede elétrica por ser espécies de porte grande o local onde foram plantadas, não é adequado com o espasamente quanto à largura das calçadas, ruas e rede elétrica.

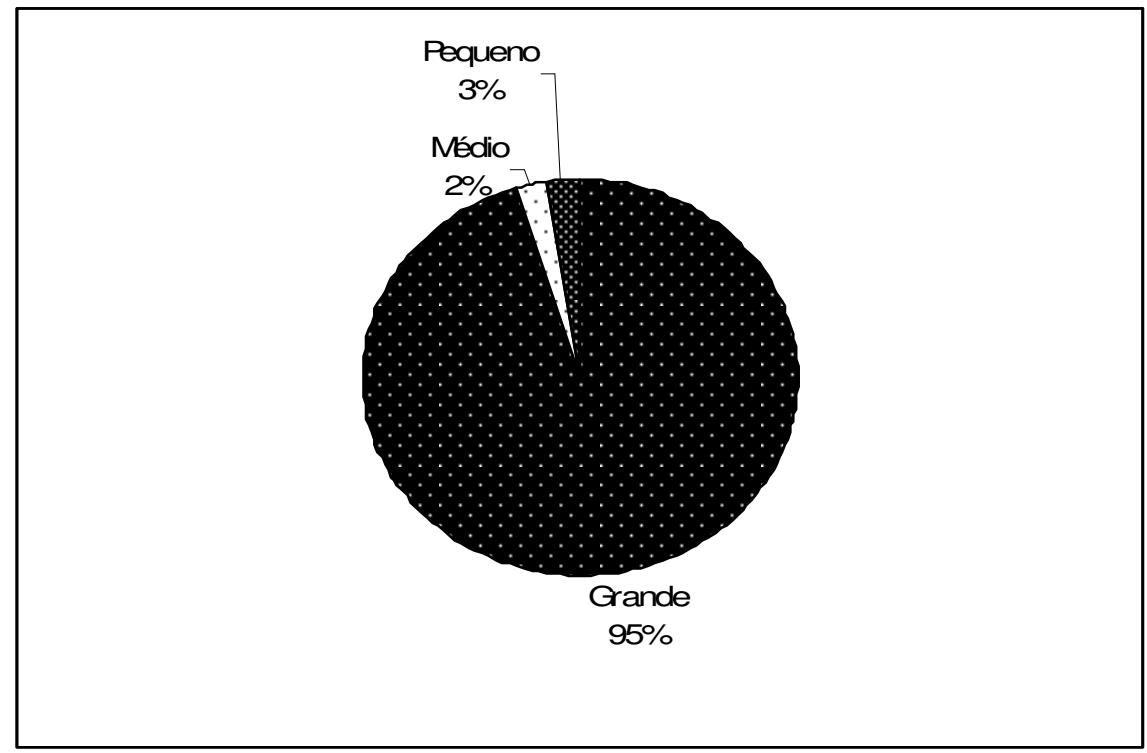

FIGURA 07-Percentagens dos indivíduos arbóreos levantados quanto ao porte

\section{COSIDERAÇÔES FINAIS}

Ao realizar esse estudo, buscou-se fazer o levantamento das espécies botânicas e as condições da arborização urbana do município de Cacoal-RO, sendo obtidos os seguintes resultados:

- 20 famílias botânicas foram levantadas distribuídas em 45 espécies, sendo a família que apresentou maior número de espécies foi a Leguminosae com 9 espécies;

- As espécies Ficus benjamina, Letônia tomentosa e Senna, spectabili, representam $80,18 \%$ dos indivíduos levantados;

- Quanto ao porte, 95\% dos indivíduos amostrados são de grande porte;

- Quanto aos danos causados a calçadas observou-se que $60,79 \%$ das árvores avaliadas causaram algum tipo de dano às calçadas devido ao seu grande porte;

- Quanto à disposição das árvores avaliadas plantadas sob a fiação elétrica, das 1.237 plantadas sob fiação elétrica $56,10 \%$ interfere na fiação elétrica; 
- Foram encontradas 722 árvores plantadas irregularmente quanto ao critério distância entre estas e as garagens residenciais e 131 árvores quanto à distância destas as esquinas e posto de iluminação.

\section{RECOMENDAÇÕES:}

Deve-se planejar o plantio das árvores no perímetro urbano tomando como base os critérios técnicos adequados de forma a reduzir os danos materiais (danos a muros e calçadas) e não colocando em risco vidas humanas quanto à obstrução da visibilidade de motoristas e ou acidentes com a rede elétrica.

A população deve ser orientada, através de educação ambiental, sobre podas mal executadas e os danos causados nos exemplares, os benefícios da arborização urbana e a introdução de calçada verde como espécies nativas do Brasil visando a melhoria do ambiente urbano, tanto para a árvore como para a população.

\section{REFERÊNCIAS}

Angiosperm Phylogeny Group (APG) II. An update of the Angiosperm Phylogeny Group classification for the orders and families of flowering plants:APGII. Botanical Journal of the Linnean Society v.141, 2003. p.399-436.

BORTOLETO, S; SILVA FILHO, D. F; LIMA, A. M L. P. Prioridades de Manejo para a Arborização Viária da Estância de Águas de São Pedro-SP. Revista da Sociedade Brasileira de Arborização Urbana. Volume 1, número 1, 2006.73p.

CEMIG /IEF.Manual de arborização.Belo Horizonte: (2001) 40p.

COUTO, S. C. Inventário e Diagnóstico da Arborização Urbana do Bairro de Benfica, Município Seropédica - Rio de Janeiro-2006.54p.

DANTAS I. C.; SOUZA C. M. C. Arborização urbana na cidade de Campina Grande inventário e suas espécies pb: Revista de biologia e ciências da terra Volume 4 - Número 2, 2004. 18p.

IBGE.http://www.ibge.gov/estatística/população/censo 2008, Disponível na internet.Online.13 de novembro 2009.1p.

KEMPER. Prefeitura Municipal de Cacoal. Plano Municipal de Desenvolvimento Urbano Sustentável. Cacoal: PHDUG, 2002.25p.

LIMA, A. M. L. P. Árvores de Rua. Revista Globo Ciência, São Paulo, № 44, Março de 1995. 25p. 
LIRA, R. S; DANTAS, I. C; CAVALCANTI, M. L. F; BARROS, M. J. B; LIRA, V. M. L. e CARNEIRO P. T. - Diagnóstico paisagístico do Parque da Criança em Campina Grande-PB. Revista de Biologia e Ciências da Terra. Volume 4 - Número 1- 2004. 23p.

LORENZI, H. Árvores Brasileiras - manual de identificação e cultivo de plantas arbóreas nativas do Brasil - Vol. 01 - 4. edição. Nova Odessa, SP: Instituto Plantarum. 2002. 384 p.

LORENZI, H. Árvores Brasileiras - manual de identificação e cultivo de plantas arbóreas nativas do Brasil - Vol 02 - 2. edição. Nova Odessa, SP: Instituto Plantarum. 2002. 384 p.

LORENZI, H.; SOUZA, H.M., J.T. de Medeiros Costa, L.S.C. de Cerqueira \& E. Ferreira. Palmeiras Brasileiras e Exóticas Cultivadas. Nova Odessa, SP: Instituto Plantarum. 2004. $432 \mathrm{p}$.

LORENZI, H.; SOUZA, H.M. Plantas Ornamentais no Brasil - arbustivas, herbáceas e trepadeiras. 3ª edição. Nova Odessa - SP: Instituto Plantarum. 2001,1120 p.

MARTO, G. B.T. Arborização urbana Instituto de Pesquisas e Estudos Florestais IPEFLCF/ESALQ/USP, Piracicaba -SP - 2006. 5p.

MATTER, G. Paisagismo no Brasil: disponível em http: //www. Paisagismobrasil.com.br/ index.php?System=new \& neus. Ed.7928 actian=read. Acesso em 12 de setembro de 2007.1p.

MICHI, S. M. P. COUTO H. T. Z. Estudo de dois Métodos de Amostragem de árvores de rua na cidade de Piracicaba - SP- 1ํㅡㄴ Curso em Treinamento sobre Poda em Espécies Arbóreas Florestais e de Arborização Urbana, 1996. 10p.

OLIVEIRA, E.Z. A percepção ambiental da arborização urbana dos usuários da avenida Afonso Pena entre as ruas Calógeras e Ceará da cidade de Campo Grande-MS. Campo Grande, UNIDERP, 2005. 125p.

PIVETTA, K. F. L. SILVA, FILHO, D. F; Série Arborização Urbana. BOLETIM ACADÊMICO UNESP/ FCAV /FUNEP - Jaboticabal-SP - 2002. 69p.

PREFEITURA MUNICIPAL DE CACOAL. Plano Municipal de Desenvolvimento Urbano. Cacoal, 2009.1p.

RIBEIRO, C. Árvores floríferas no Brasil: disponível em ttp://www.Jardimdeflores.com.br /http: paisagismo.htm. Acesso em 12 de setembro de 2007.1p.

SECRETARIA DO VERDE E DO MEIO AMBIENTE, programa de arborização urbana. Ampliação e Re-qualificação da Cobertura Vegetal do Município de São Paulo, 2005. 19p.

TEIXEIRA, I. F. Análise Qualitativa da Arborização de Ruas do Conjunto Habitacional Tancredo Neves, Santa Maria - RS- Ciência Florestal, v. 9, n. 2,1999. 9-21p. 